Vol. 4 No.2 Juni 2021

Rang Teknik Journal

http://jurnal.umsb.ac.id/index.php/RANGTEKNIKJOURNAL

\title{
Studi Eskperimental Efektifitas Penggunaan Zat Adiktif Fosroc SP 337 Pada Beton
}

\author{
Arman. A ${ }^{1}$, Arif Oftan ${ }^{2}$ \\ Dosen Jurusan Teknik Sipil, Fakultas Teknik Sipil dan Perencanaan ${ }^{1}$, Mahasiswa Jurusan Teknik \\ Sipil, Fakultas Teknik Sipil dan Perencanaan Institut Teknologi Padang ${ }^{2}$ \\ DOI: http://dx.doi.org/10.31869/rtj.v4i2.2557
}

\begin{abstract}
Abstrak:Beton merupakan salah satu item yang memegang peranan penting dalam struktur baik itu gedung, jembatan, bendungan, dan bangunan sipil lainnya. Beton dapat diartikan sebagai campuran antara semen Portland atau semen hidraulik yang lain, agregat halus, agregat kasar dan air dengan atau tampa bahan tambah membentuk massa padat (SNI 03-2834-2000). Beton mutu tinggi (high strength concrete) atau sering di sebut juga beton kinerja tinggi memiliki kinerja dan sifat - sifat yang lebih unggul dibanfingkan dengan beton normal. Menurut American Concrete Institute (ACI) Committee 363, beton mutu tinggi adalah beton dengan kuat tekan diatas 6000 Psi (40 MPa). Untuk meningkatkan kualitas beton perlu dilakukan berbagai upaya dan inovasi agar mendapatkan mutu beton yang maximal. Inovasi dilakukan dalam penelitian ini dengan menambahkan Zat Adiktif SP 337 dalam adonan beton. Berdasarkan brosur Fosroc, Conplast SP 337 baik untuk meningkatkan kekuatan atau untuk menghasilkan beton kemampuan kerja tinggi atau mengurangi kandungan semen beton atau untuk memperlambat waktu pengerasan beton. Penggunakan zat adiktif fosroc sp 337 di dalam penelitian ini dengan komposisi $0,0 \%, 1,5 \%$, dan 2,5\% dari berat jenis semen. Setiap variasi campuran terdapat 3 sampel benda uji. Dari hasil pengujian kuat tekan terjadi kenaikan kuat tekan rata-rata perbedaan nilai yang cukup jauh pada umur 7 hari antara campuran zat adiktif Fosroc SP $3370 \%$ dengan kuat tekan rata - rata sebesar $16,48 \mathrm{MPa}$, campuran $1,5 \%$ kuat tekan rata - rata sebesar 21,89 MPa, dan 2,5\% dengan kuat tekan rata - rata sebesar 24,19 MPa. Sedangkan pada umur pengujuan 28 hari kuat tekan rata - rata setiap variasi campuran Fosroc SP 337 hampir saling mendekati, ini dapat kita analisa pada tabel 4.19, 4.20, 4.21 dengan data campuran (0\%) memiliki kuat tekan rata - rata 34,43 $\mathrm{MPa}$, campuran (1,5\%) memiliki kuat tekan rata 35,68 $\mathrm{MPa}$, dan campuran $(2,5 \%)$ memiliki kuat tekan rata-rata 38,89 Mpa. Hal ini diakibatkan oleh sifat zat adiktif Fosroc SP 337 yang mempercepat dan menambah kuat tekan di awal umur beton. Kuat tekan rata rata paling tinggi ialah campuran $2,5 \%$.
\end{abstract}

Kata kunci : Beton, Efektivitas, Fosroc SP 337

\section{PENDAHULUAN \\ Latar Belakang}

Beton merupakan salah satu item yang memegang peranan penting dalam struktur baik itu gedung, jembatan, bendungan, dan bangunan sipil lainnya. Dalam beberapa kasus pembangunan gedung bertingat tinggi maupun jembatan dengan bentang yang panjang membutuhkan beton mutu tinggi untuk mendukung kekuatan dari struktur tersebut. "Beton performa tinggi yang secara umum memiliki kuat tekan 6000 psi (40 MPa) atau lebih. Ukuran kuat tekannya diperoleh dari silinder beton $150 \mathrm{~mm}-300 \mathrm{~mm}$ atau silinder $100 \mathrm{~mm}-200 \mathrm{~mm}$ pada umur 56 ataupun 90 hari, ataupun umur yang telah ditentukan tergantung pada aplikasi yang diingingkan." (Arman. A, Herix. S, dan Kartika. A, 2017)
Untuk menciptakan beton bermutu tinggi perlu di lakukan pengurangan porositas beton dengan cara mengurangi kadar air saat proses pembutan beton, penggunaan semen yang lebih banyak dari pada beton normal, serta campuran agregat yang telah memenuhi standar. Untuk menekan biaya pembuatan beton mutu tinggi ini, maka di gunakan campuran zat adiktif Fosroc Conplast $\mathrm{R}$ yang berfungsi untuk mengurangi penggunaan kadar semen tanpa harus mempengaruhi kuat tekan beton. Dalam mengaplikasikan zat adiktif ini ke dalam campuran adonan beton maka di perlukan formula yang tepat untuk mendapatkan hasil yang maximal. Untuk mendapatkan fomula tersebut perlu dilakukanya sebuah penelitian. 


\section{Rumusan Masalah}

Berdasarkan latar belakang yang telah diuraikan di atas, maka dapat diambil rumusan masalah efektivitas penggunaan Fosroc Conplast $\mathrm{R}$ yang tepat pada beton mutu tinggi.

\section{Tujuan dan Manfaat Penelitian}

Penelitian ini bertujuan untuk mengetahui persentase penggunaan paling efektif dari zat adiktif Fosroc Conplast $\mathrm{R}$ pada campuran beton mutu tinggi, adapun manfaat dari penelitian ini adalah menemukan campuran yg tepat dan efektif sehingga bisa diaplikasikan dilapangan.

\section{Batasan Masalah}

Adapun batasan masalah pada penelitian ini adalah:

1. Kuat tekan beton mutu tinggi

2. Agregat halus dan agregat kasar berasal CV. Berkah.

3. Semen yang di gunakan adalah Semen tipe I produksi PT.Semen Padang.

4. Persentase pengaplikasian zat adiktif Fosroc Conplast R 0,0\%, 1,5\%, 2,5\%.

5. Air yang di gunakan adalah air sumur bor ITP.

6. Benda uji dengan cetak Silinder ukuran 15 $\mathrm{cm} \times 30 \mathrm{~cm}$.

7. Pengujian kuat tekan beton pada umur 28 hari.

8. Tempat penelitian dilakukan di Labor Teknik Sipil ITP dan Laboratorium Dinas PU Provinsi Sumatera Barat.

\section{TINJAUAN PUSTAKA \\ Beton Mutu Tinggi}

Menurut Standar Nasional Indonsesia (SNI 03-2847-2002), beton adalah campuran antara semen portland atau semen hidraulik lain, agregat halus, agregat kasar dan air dengan atau tanpa bahan tambahan yang membentuk massa padat. Pada bangunan tinggi mengurangi beban mati. Kelemahannya adalah kegetasannya. Beton banyak di gunakan pada infrastrutur - infrastruktur seperti gedung, jembatan, bendungan, apron, dermaga, silo, cerobong, terowongan, dan lain sebagainya. dan beton pratekan. Hal ini disebabkan karana beton mutu tinggi memiliki kuat tekan yang lebih tinggi dibandingakan dengan beton nomal sehingga dimensi dari elemen struktur dapat lebih ramping dan memberikan ruangan yang lega.

\section{Standar SNI 03-2834-2000}

Tata cara ini meliputi persyaratan umum dan persyaratan teknis perencanaan proporsi campuran beton untuk digunakan sebagai salah satu acuan bagi para perencana dan pelaksana dalam merencanakan proporsi campuran beton tanpa menggunakan bahan tambah untuk menghasilkan mutu beton sesuai dengan rencana.

\section{Zat Adiktif}

Menurut Ridwan dan Arman (2018) Zat adiktif merupakan bahan tambahan yang di campuran kedalam adonan beton. Penambahan ini bertujuan untuk memeperbaiki sifat - sifat tertentu dari campuran beton keras dan lunak. Zat adit ini tidak dapat mengkoreksi komposisi spesi beton yang buruk, maka dari itu di perlukan komposisi yang optimal agar dendapatkan hasil yang efektif saat menggunakan bahan tambahan ini. Penggunaan zat adiktif hanya $10 \%$ - $20 \%$ dari berat jenis semen.

\section{Fosroc SP 337}

Berdasarkan brosur Fosroc SP 337 baik untuk meningkatkan kekuatan atau untuk menghasilkan beton kemampuan kerja tinggi atau mengurangi kandungan semen beton atau untuk memperlambat waktu pengerasan beton.

Kegunaan:

a. Menghasilkan beton workability tinggi tanpa kehilangan kekuatan.

b. Untuk mempromosikan kekuatan awal dan akhir yang tinggi dengan memanfaatkan pengurangan air sementara menjaga kemampuan kerja.

c. Menghasilkan beton berkualitas tinggi dengan daya tahan yang lebih baik dan kedap air.

d. Pada dosis yang lebih tinggi, keuntungan dapat diambil dari keterlambatan waktu pengaturan awal beton khususnya dalam jumlah besar.

Keuntungan:

a. Peningkatan kemampuan kerja membuat lebih mudah dan penempatan yang lebih cepat serta pemadatan yang optimal.

b. Memberikan kekuatan yang lebih tinggi tanpa peningkatan kadar semen atau pengurangan kemungkinan untuk 
dilaksanakan. Ideal untuk produksi beton pracetak.

c. Mengurangi kecepatan kehilangan kemampuan kerja biasanya terkait dengan superplasticiser.

d. Mengurangi retak susut karena rasio air semen yang lebih rendah. Membuat air beton kedap air.

e. Memperbaiki ketahanan dan impermeabilitas beton.

f. Aman pada beton prategang produksi.

\section{METODOLOGI PENELITIAN Prosedur penelitian}

Secara garis besar prosedur penelitian ini mempunyai tahapan yang bisa dilihat pada bagan alir dibawah ini:

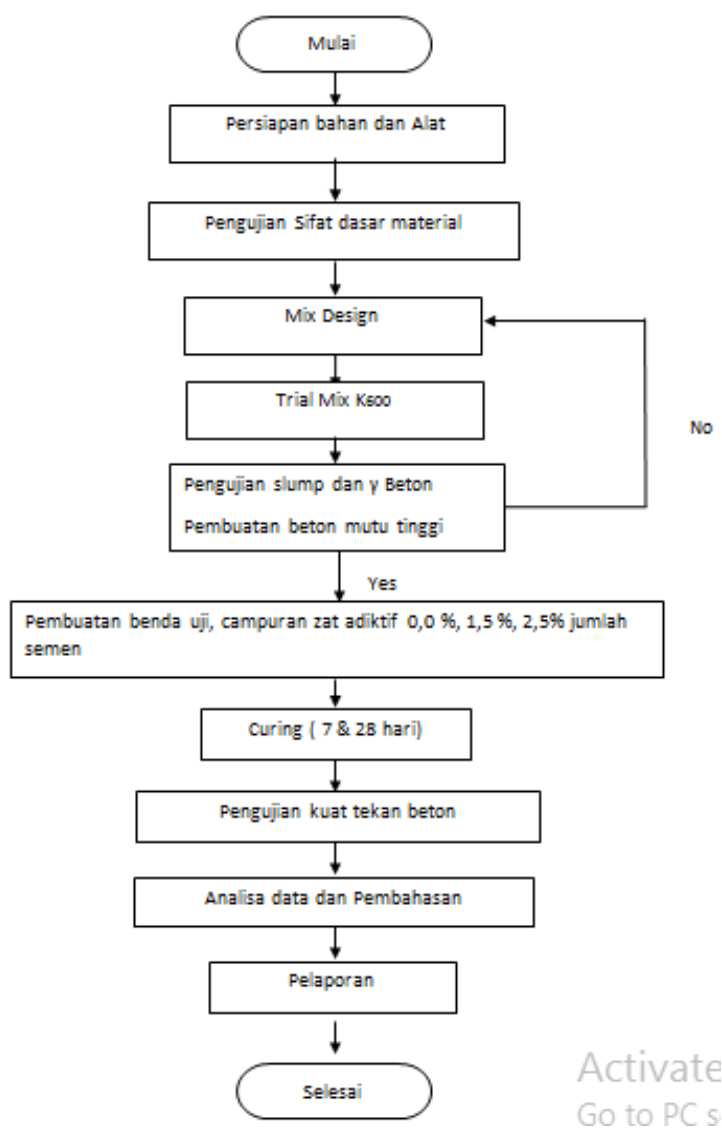

Gambar 1 Bagan Alir Pelaksanaan Penelitian

\section{Bahan Penelitian}

1 Semen Portland tipe I produksi PT. Semen Padang.

2 Agregat halus yaitu pasir alam berasal dari alisan sungai Gunung Nago.

3 Agregat kasar (split) dalam penelitian ini didapat dari CV. Berkah.

4 Fosroc SP 337 didapatkan dari Distributor Fosroc Indonesia.

5 Air bersih

\section{Peralatan Penelitian}

1. Pada pengujian agregat peralatan yang digunakan: ayakan/saringan, gelas ukur, timbangan, tabung silinder, oven, dan mesin penggetar

2. Peralatan untuk pembuatan benda uji: ember dan napan, concrete mixer, cetakan kubus, kuas dan palu karet, jangka sorong.

3. Peralatan pengujian benda uji: kerucut Abrams, batang penumbuk dan mistar, Universal Testing Machine (UTM).

\section{Benda Uji}

Dalam penelitian ini sampel atau benda uji dibuat berbentuk silinder dengan ukuran 30 x $15 \mathrm{~cm}$ sebanyak delapan belas sampel.

Tabel 1 Tabel Benda Uji

\begin{tabular}{l|c|c|c}
\hline \multirow{2}{*}{$\begin{array}{l}\text { Campuran Beton } \\
\text { Fosroc SP337 }\end{array}$} & \multicolumn{2}{|c|}{$\begin{array}{c}\text { Umur } \\
\text { Pengujian }\end{array}$} & Jumlah \\
\cline { 2 - 3 } & $\begin{array}{c}28 \\
\text { hari }\end{array}$ & hari & \\
\hline $\begin{array}{l}\text { Beton dengan zat } \\
\text { adiktif sebesar } \\
0,0 \%\end{array}$ & 3 & 3 & 6 \\
\hline $\begin{array}{l}\text { Beton dengan zat } \\
\text { adiktif sebesar } \\
1,5 \%\end{array}$ & 3 & 3 & 6 \\
\hline $\begin{array}{l}\text { Beton dengan zat } \\
\text { adiktif sebesar }\end{array}$ & 3 & 3 & 6 \\
$\begin{array}{l}2,5 \% \\
\text { Total Jumlah Sampel }\end{array}$ & 18 \\
\hline
\end{tabular}

\section{Pelaksanaan Penelitian}

Proses pelaksanaan penelitian diawali dengan pengadaan material (agregat halus adalah pasir dan agregat kasar adalah kerikil). Setelah material didapat, dilakukan pengujian sifat dasarnya :

1. Pemeriksaan gradasi agregat

2. Pemeriksaan kotoran agregat

3. Pemeriksaan passing no. 200

4. Pemeriksaan berat isi agregat

5. Pemeriksaan berat jenis dan penyerapan agregat

6. Pemeriksaan keausan agregat dengan mesin Los Angeles.

Setelah pengujian dasar agregat langkah berikutnya merencanakan rancangan campuran beton (mix design) berdasarkan metoda SNI 03-2834-2000. Dari data rancangan campuran beton yang didapat maka pekerjaan berikutnya adalah membuat benda uji sebanyak jumlah sampel yang dibutuhkan. Untuk mendapatkan 
bentuk benda uji digunakan silinder ukuran 30 x $15 \mathrm{~cm}$. Selama umur beton rencana, perawatan beton (curing) dilakukan dengan cara merendam benda uji didalam bak perendam. Setelah itu lakukakan pengujian kuat tekan beton dengan Universal Testing Machine (UTM) jika umur rencana telah terpenuhi. Berdasarkan hasil dari data pengujian kuat tekan perkerjaan terakhir adalah menganalisis data tersebut untuk mendapatkan sebuah kesimpulan.

\section{HASIL PENELITIAN DAN PEM} BAHASAN

\section{Pengujian Agregat Halus}

Pada pemeriksaan agregat halus diperoleh hasil bahwa agregat halus yang digunakan memenuhi spesifikasi gradasi sesuai standar AASHTO T27, masuk pada zona II (pasir kasar) dengan modulus kehalusan $(\mathrm{fm})=3,7$. Kadar kotoran organik didapat warna No.2 masih berada pada batas normal sesuai SNI 2816-2014. Pemeriksaan lolos saringan No.200 sebesar 3,998\% berarti aggregat halus mempunyai kandungan lumpur di bawah batas maksimal 5\% (SNI ASTM C117:2012). Berat isi aggregat halus sebesar $1,37 \mathrm{gr} / \mathrm{cm}^{3}$, hal ini menunjukkan bahwa pasir memenuhi standar SNI 1973:2008 dengan standar minimum 1,2 $\mathrm{gr} / \mathrm{cm}^{3}$. Berat jenis pada pasir kering sebesar 2,33 , berat jenis SSD 2,43, berat jenis apparent 2,58 , dan penyerapan air $4,17 \%$, terlihat bahwa berat jenis pasir memenuhi SNI 1970:2008 dengan BJ minimum 2,3 dan penyerapan air maksimal $5 \%$.

\section{Pengujian Agregat Kasar}

Dari pemeriksaan agregat kasar yang dilakukan diperoleh agregat kasar yang digunakan dalam penelitian ini memenuhi spesifikasi gradasi sesuai standar SNI 032834-2000 dengan modulus kehalusan 5,95. Passing No.200 sebesar 0,98\%, berarti agregat kasar memenuhi spesifikasi yaitu dibaawah batas maksimum 1\% (SNI 03-4142-1996). Berat isi agregat kasar $1,64 \mathrm{gr} / \mathrm{cm}^{3}$, memenuhi standar minimum $1,2 \mathrm{gr} / \mathrm{cm}^{3}$ sesuai SNI 1973:2008. Berat jenis kering didapat 2,58, berat jenis SSD 2,64, berat jenis apparent 2,75, dan penyerapan 2,4 , terlihat bahwa berat jenis agregat kasar memenuhi standar SNI 1970:2008 dengan BJ minimum 2,3 dan penyerapan air maksimum 5\%. Keausan aggregat dengan mesin Los Angeles diperoleh sebesar 19,06\%, memenuhi standar batas maksimum yang diizinkan $27 \%$ - 30\% sesuai PB-0206-76.

\section{Perencanaan Campuran Beton (Mix Design)}

Dalam perencanaan campuran beton didapatkan komposisi campuran beton dengan penambahan zat adiktif Fosroc SP 337 untuk 3 benda uji yaitu:

Tabel 2 Komposisi Campuran Beton Normal

\begin{tabular}{r|l|r}
\hline No & Komposisi Bahan/M & \multicolumn{1}{|c}{$\begin{array}{c}\text { Berat } \\
(\mathrm{Kg})\end{array}$} \\
\hline 1 & Semen & 11.78 \\
\hline 2 & Air & 3,36 \\
\hline 3 & Pasir & 12,97 \\
\hline 4 & Split & 12,46 \\
\hline
\end{tabular}

Tabel 3 Penambahan Zat Adiktif

\begin{tabular}{r|r}
\hline $\begin{array}{c}\text { Fosroc SP 337 } \\
\text { sebesar 1,5\% }\end{array}$ & $\begin{array}{c}\text { Fosroc SP 337 } \\
\text { sebesar 2,5\% }\end{array}$ \\
\hline $150 \mathrm{Gr}$ & $250 \mathrm{Gr}$ \\
\hline
\end{tabular}

\section{Pengujian Kuat Tekan Beton}

Dari hasil pengujian kuat tekan yang dilakukan dilaboratorium, didapatkan nilai kuat tekan sebagai berikut:

Tabel 4 Hasil Kuat Tekan Beton Rata-rata

\begin{tabular}{|c|c|c|}
\hline \multirow{2}{*}{$\begin{array}{c}\text { Penambahan Zat } \\
\text { Adiktif Fosroc SP337 } \\
0,0 \%, 1,5 \% \text {, dan } 2,5 \%\end{array}$} & \multicolumn{2}{|c|}{$\begin{array}{l}\text { Kuat Tekan Beton } \\
\text { Rata-rata }\left(\mathrm{N} / \mathrm{mm}^{2}\right)\end{array}$} \\
\hline & 7 hari & 28 hari \\
\hline $0,0 \%$ (Normal) & 25,28 & 34,26 \\
\hline $1,5 \%$ & 31,61 & 35,54 \\
\hline $2,5 \%$ & 37,06 & 39,42 \\
\hline
\end{tabular}

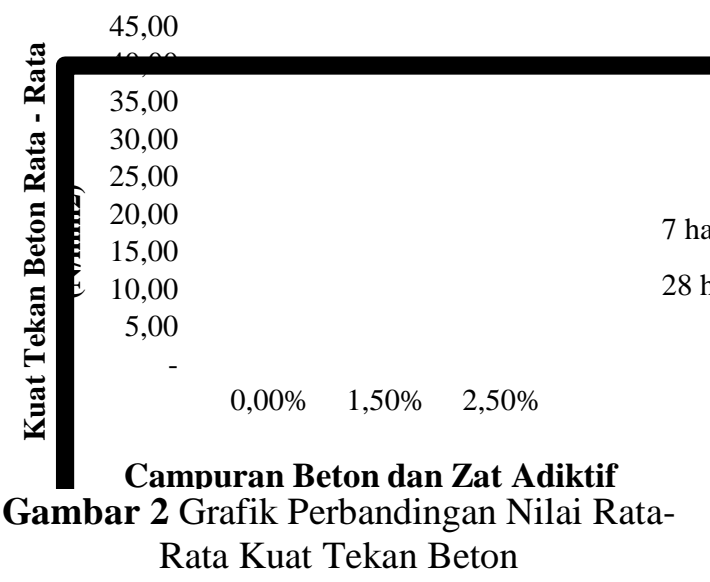




\section{PENUTUP}

Berdasarkan hasil penelitian dengan membahas efektifitas penggunaan zat adiktif Forsroc SP $3370,0 \%, 1,5 \%$, dan $2,5 \%$ terhadap kuat tekan beton maka dapat ditarik kesimpulan sebagai berikut:

1. Nilai kuat tekan rata - rata beton pada umur 7 hari dengan campuran zat adiktif Fosroc SP $3370 \%$ 25,28 MPa, 1,5\% 31,61 MPa, dan 2,5\% 37,06 MPa. Dan pada umur rencana 28 hari kuat tekan rata - rata beton dengan campuran Fosroc SP 337 0\% 34,26 $\mathrm{MPa}, 1,5 \% 35,54 \mathrm{MPa}$, dan 2,5\% 39,42 $\mathrm{MPa}$

2. Dari data di atas dapat di tarik kesimpulan semakin banyak penggunaan zat adiktif Fosroc SP 337 maka kuat tekannya meningkat.

3. Nilai persentase optimum dari penambahan zat adiktif Fosroc SP 337 adalah 2,5\%. Ini dikarenakan nilai kuat teka tertinggi dipapatkan dengan persentase ini.

\section{DAFTAR PUSTAKA}

Arman, A., Cici, Ramayanti., 2018. Studi Eksperimental Metoda Pembuatan Beton Instan $F c^{\prime}=25$ Mpa Dengan Penambahan Zat Adiktiffosroc Sp 337 \& Fosroc Conplast $R$. Padang. Institut Teknologi Padang.

Arman, A., Herix, Sonata., Kartika, Ananda., Agustus 2017. Studi Eskperimental Setting Time Beton Mutu Tinggi Menggunakan Zat Adiktif Fosroc Sp 337 \& Fosroc Conplast R.Padang. Institut Teknologi Padang.

Ardon Rahimi. 2015. "Studi Eksperiment Evaluasi Pengaruh Penambahan Serat Nylon Terhadap Kuat Tarik Beton Normal", Padang : Institut Teknologi Padang.

AASHTO. Standard Methode of Test for Sieve Analysis of Fine and Coarse Agreggate. AASHTO T-27. Amerik

ACI Committee 363R-92., 1997. State of the Art Report on High StrengthConcrete (ACI 363R-92): An ACI Standard: Commentary on Building Code Requirements for Structural Concrete (ACI 363R-92), an ACI Report.American Concrete Institute

ASTM C-33-93, "Standard Spesificationfor Concretes Aggregates" American Society for Testing and Materials, Philadelphia, Pennsylvania.

ASTM C150, Standart Spesification for Portland Cement. (1985). Annual Books of ASTM Standards. Philadelphia-USA.

[BSN] Badan Standarisasi Nasional. 2004. SNI ASTM C117 : 2004 Metode Uji Bahan Yang Lebih Halus Dari Saringan 75um (No.200) Dalam Agregat Mineral Dengan Pencucian. Badan Standarisasi Nasional. Jakarta.

[BSN] Badan Standarisasi Nasional., 2000. SNI 03-6468: Tata Cara Perencanaan Beton kekuatan dengan Semen Portland dan Abu Terbang. Badan standarsisasi Nasional. Jakarta.

[BSN] Badan Standarisasi Nasional, 2000. SNI 03-287-2002 : Tata Cara Menghitung Struktur Beton Untuk Gedung (Beta Version). Badan Sandarisasi Nasional. Bandung.

[BSN] Badan Stndarindarisasi Nasional., 2015. SNI 03i-2049: Semen Portlan. Badan Standarsisasi Nasioarisnal. Jakarta

[BSN] Badan Standarisasi Nasional., 2000. SNI 03-2834-2000: Tata Cara Pembuatan Rencana Campuran Beton Normal. Badan Standar Nasional.

[BSN] Badan Standarisasi Nasional., 2014. SNI 2816:2014: Metode Uji Bahan Organik Dalam Agregat Untuk Beton. Badan Standarsisasi Nasional.

[BSN] Badan Standarisasi Nasional. 2008. SNI 1973-2008 Metode Pengujian Berau isi Beton. Badan Standarisasasi Nasional. Jakarta.

[BSN] Badan Standarisasi Nasional. 2008. SNI 1970-2008 "Metode Pengujian Berat Jenis Dan Penyerapan AirAgregat Halus. Badan Standarisasi Nasional. Jakarta.

Departemen Pemukiman dan Prasana Wilayah. 2004. PD T-04-2004-C: Tata Cara Pembuatan dan Pelaksanaan Beton BerkekuatanTinggi.Direktorat Jenderal Industri Agro Kementerian Perindustrian Jakarta, 2010

Ir. Tri Mulyono, MT,(2005), ${ }^{\text {CeTeknologi }}$ Beton", Andi, Yogyakarta.

Nawy., 1985. Beton bertulang Suatu Pendekatan Dasar. PT. Refika aditama. Bandung. 
Muhammad, Ridwan., dan Arman, A,. 2018. Beton Bertulag I. Padang: Institut Teknologi Padang.

Mulyono,HAM. 2005. Kamus Kimia. Cetakan ke-3 Jakarta : Bumi aksara

Mulyono Tri. Ir, Teknologi Beton, Fakultas Teknik Universitas Negeri Jakarta,Jakarta, 2003.

Pramono, Didiek; Suryadi HS.Bahan Konstruksi Teknik, Penerbit Universitas Gunadarma, Jakarta, 1998

Rindengan dkk. (1995). Karakteristik buah kelapa hibrida untuk bahan baku industri. Laporan hasil penelitian kerjasama proyek pembinaan kelembagaan penelitian pertanian nasional. Badan litbang 49p. 